\title{
Inhaled steroid/long-acting $\beta 2$ agonist combination products provide 24 hours improvement in lung function in adult asthmatic patients
}

\author{
Jan Lötvall ${ }^{1}$, Stephen Langley ${ }^{2,4}$ and Ashley Woodcock*3
}

Address: ${ }^{1}$ Department of Internal Medicine/Respiratory Medicine and Allergology, Sahlgrenska Academy, Göteborg University, Sweden, ${ }^{2}$ Medicines Evaluation Unit, North West Lung Centre, Wythenshawe Hospital, Manchester, UK, 3 University of Manchester, Manchester, UK and ${ }^{4}$ Deceased

Email: Jan Lötvall - jan.lotvall@mailer.mednet.gu.se; Stephen Langley - woodyprof@aol.com; Ashley Woodcock* - ashley.a.woodcock@manchester.ac.uk

* Corresponding author

Published: 18 August 2006

Respiratory Research 2006, 7:110 doi:10.1186/1465-9921-7-110
Received: 29 December 2005

Accepted: 18 August 2006

This article is available from: http://respiratory-research.com/content/7/I/II0

(C) 2006 Lötvall et al; licensee BioMed Central Ltd.

This is an Open Access article distributed under the terms of the Creative Commons Attribution License (http://creativecommons.org/licenses/by/2.0), which permits unrestricted use, distribution, and reproduction in any medium, provided the original work is properly cited.

\begin{abstract}
Background: The combination of inhaled corticosteroids (ICS) and long-acting $\beta 2$-agonists (LABA) is recommended by treatment guidelines for the treatment of persistent asthma. Two such combination products, salmeterol/fluticasone propionate (SFC, Seretide ${ }^{\mathrm{TM}} \mathrm{GSK}$, UK) and formoterol/budesonide (FBC, Symbicort ${ }^{\mathrm{TM}}$, AstraZeneca, UK) are commercially available.

Objectives: The purpose of these studies was to evaluate and compare the duration of bronchodilation of both combination products up to 24 hours after a single dose.

Methods: Two randomised, double blind, placebo-controlled, crossover studies were performed. Study A was conducted in 33 asthmatic adults receiving $400-1200 \mathrm{mcg}$ of budesonide or equivalent. Serial forced expiratory volume in one second $\left(\mathrm{FEV}_{1}\right)$ was measured over 24 hours to determine the duration of effect of both SFC $(50 / 100 \mathrm{mcg})$ and FBC $(4.5 / 160 \mathrm{mcg})$. Study B was conducted in 75 asthmatic adults receiving $800-1200 \mathrm{mcg}$ of budesonide or equivalent and comprised a 4 week run-in of $400 \mathrm{mcg}$ bd Becotide ${ }^{\mathrm{TM}}$ followed by 4 weeks treatment with either SFC $50 / 100 \mathrm{mcg}$ bd or FBC $4.5 / 160 \mathrm{mcg}$ bd taken in a cross-over manner. Serial 24-hour FEV, was measured after the first dose and the last dose after each 4-weeks treatment period to determine the offset of action of each treatment.
\end{abstract}

Results: In study A, a single inhalation of SFC and FBC produced a sustained bronchodilation at 16 hours with an adjusted mean increase in $\mathrm{FEV}$, from pre-dose of $0.22 \mathrm{~L}(95 \% \mathrm{Cl} 0.19,0.35 \mathrm{~L})$ for SFC and $0.25 \mathrm{~L}(95 \% \mathrm{Cl} 0.2 \mathrm{I}, 0.37 \mathrm{~L})$ for $\mathrm{FBC}$, which was significantly greater than placebo for both treatments $(-0.05 \mathrm{~L} ; \mathrm{p}<0.00 \mathrm{I})$. In study $\mathrm{B}$, the slope of decline in FEV , from 2-24 hours post dose was $-16.0 \mathrm{ml} / \mathrm{hr}$ for SFC and $-14.2 \mathrm{ml} / \mathrm{hr}$ for FBC. The weighted mean AUC over 24 hours was $0.2 \mathrm{I}$ Lxmin and 0.22 Lxmin and mean change from pre-dose FEV 1 at 12 hours was $0.21 \mathrm{~L}$ for SFC and $0.20 \mathrm{~L}$ for FBC respectively

Conclusion: Both SFC and FBC produced a similar sustained bronchodilator effect which was prolonged beyond 12 hours post dose and was clearly measurable at $24 \mathrm{~h}$. 


\section{Background}

The benefit of adding a long-acting $\beta 2$-agonist (LABA) to inhaled corticosteroid therapy (ICS) in the treatment of asthma is well-established [1-3]. Two such combinations, salmeterol xinafoate and fluticasone propionate (SFC, Seretide ${ }^{\mathrm{TM}}$ ) and formoterol and budesonide (FBC, Symbicort $^{\mathrm{TM}}$ ) are widely used and have been shown to be effective in controlling asthma of varying severity in adults and children [4-8]. A limited number of studies have compared these two combination products $[9,10]$, and the data imply some different clinical profiles due to the different pharmacological properties of the ICS and LABAs [9,11-13].

When taken on a regular basis, both SFC and FBC have shown clinical efficacy compared to placebo in patients with mild to moderate asthma $[14,15]$. We therefore aimed to evaluate and compare the bronchodilator response of SFC and FBC over a 24-hour period after single or repeated dosing. In addition, we asked whether tolerance to the bronchodilating effect of either treatment develops after regular twice-daily dosing for four weeks. This paper describes the combined results of two studies designed to meet these objectives.

\section{Subjects and methods Study design}

This data represents a combination of two studies. Study A was a single centre, double blind, randomised, singledose, placebo-controlled, 3-way crossover study conducted in Sweden. Study B was performed at three centres in the UK and was a double blind, randomised, 2-way, 4week crossover study. Both studies were conducted in accordance with the Declaration of Helsinki and were subject to Ethics Committee approval prior to commencement. Written informed consent was obtained from each patient prior to the initiation of any study-related procedures.

\section{Study population}

Both studies

Adults aged $\geq 18$ years with a documented clinical diagnosis of asthma for at least 6 months prior to the study were eligible for entry. Subjects were required to have a prebronchodilator $\mathrm{FEV}_{1}$ of $>50 \%$ predicted normal and demonstrate an increase from baseline in $\mathrm{FEV}_{1}$ of at least $15 \%$ of the predicted value 15 minutes after administration of $400 \mathrm{mcg}$ of salbutamol. Subjects who were pregnant or had a smoking history of $\geq 10$ pack years, were excluded. In addition, to ensure that subjects had stable disease, any subject who had an acute asthma exacerbation requiring either oral steroid treatment or hospital treatment, a respiratory tract infection or a change in regular asthma medication within the preceding 4 weeks were excluded from both studies.

\section{Study A}

Subjects were required to be receiving $400-1200 \mathrm{mcg}$ of budesonide or equivalent for at least 4 weeks prior to the study. Subjects who had received oral $\beta 2$-agonists, slow release bronchodilators, anti-leukotrienes, sodium cromoglycate or nedocromil sodium within the preceding two weeks were excluded. Subjects were also required to stop taking long acting $\beta 2$-agonists 2 weeks prior to visit 1 .

\section{Study B}

Subjects were required to be receiving between $800-1200$ mcg of budesonide or BDP or $400-600 \mathrm{mcg} / \mathrm{day}$ of FP or QVAR for at least 4 weeks prior to the study. Subjects who had received anti-leukotrienes, theophyllines or oral, depot or parenteral corticosteroids within 4 weeks prior to visit 1 were excluded.

\section{Study treatment \\ Study A}

Subjects were randomised to receive a single dose of SFC $50 / 100 \mathrm{mcg}$ or FBC $4.5 / 160 \mathrm{mcg}$ or placebo which was administered in the Clinic. This dose of FBC is the actuated dose from a 6.0/200 mcg inhaler.

Medication was administered as one inhalation from a Diskus inhaler containing either SFC or placebo followed by one inhalation from a breath actuated device containing either FBC or placebo according to their blinded randomisation order generated. Inhalation from the Diskus was first so that the onset of action of formoterol could not be unblinded. Subjects attended the Clinic for three 24-hour intensive study days with a washout period of 37 days between study days. Subjects took their usual permitted asthma medication between study days and salbutamol was provided for relief medication.

\section{Study B}

All subjects received open label Becotide ${ }^{\mathrm{TM}} 400$ mcg twice daily during a 4 week run-in. Subjects were subsequently randomised to receive 4 weeks treatment with either SFC 50/100 mcg twice daily administered from a Diskus inhaler or FBC $4.5 / 160$ mcg twice daily from a breath actuated device. This dose of FBC is the actuated dose from a 6.0/200 mcg inhaler.

Becotide 400 mcg twice daily was given for 4-weeks during the washout period and subjects then crossed over to receive the active medication that they did not receive during the first 4-week period for a further 4-weeks. Subjects attended the Clinic for four 24-hour intensive study days on day 1 and day 28 of each treatment period. Salbutamol was provided for relief medication. 


\section{Outcome measures}

In study $\mathrm{A}, \mathrm{FEV}_{1}$ was measured pre-dose (Time 0), and then $0.5,1,2,4,6,8,10,12,14,16,20$ and 24 hours following a single morning dose of study medication. An earlier time point was not chosen as this has already been assessed in a previous study [9]. Measurements were made using a Vitalograph Spirometer, which was calibrated regularly.

In study $\mathrm{B}, \mathrm{FEV}_{1}$ was measured pre-dose and at $0.5,1,2,4$, $6,8,10,12,14,16,20$ and 24 hours following a single morning dose of study medication using a $\mathrm{KoKo}^{\mathrm{TM}}$ spirometer. Subjects were given a mini-Wright ${ }^{\mathrm{TM}}$ peak flow meter (Clement Clark, UK) to measure the highest of three morning and evening peak expiratory flow (PEF) measurements during the run-in, treatment and washout periods. Where possible, peak flow measurements were performed at the same time of day prior to study drug or use of relief salbutamol.

Safety was assessed by monitoring adverse events.

\section{Statistical analysis}

In study $\mathrm{A}$, the primary assessment of efficacy was the mean change from pre-dose $\mathrm{FEV}_{1}$ (on each study day) to 16 hours post-dose. Sixteen hours was chosen as subjects commonly have 16 hours between twice daily dose regimes. In order to detect a difference of $180 \mathrm{~mL}$ between the treatments, at a two-sided $\alpha=0.05$ significance level with $80 \%$ power, 32 subjects were required to complete all the treatment periods. Analysis of covariance appropriate for cross-over study designs which included terms for subject, treatment and period was used to estimate the treatment difference and p-value and to calculate the 95\% confidence interval for this difference.

In study $\mathrm{B}$, the primary efficacy endpoints were the slope of decline in $\mathrm{FEV}_{1}$ from 2 hours post-dose, the area under the $\mathrm{FEV}_{1}$ curve (AUC) (0-24 hours) and the mean change from pre-dose $\mathrm{FEV}_{1}$ at 12 hours post dose. Secondary endpoints were based on serial $\mathrm{FEV}_{1}$ measurements after a single dose after 4 weeks of treatment (as for the primary endpoint). The sample size was determined on the basis of anticipated differences between treatments in the mean change from pre-dose $\mathrm{FEV}_{1}$ at 12 hours, which was thought to be the least sensitive of all three endpoints. In order to detect a difference of $180 \mathrm{~mL}$ between the treatments, at a two-sided $\alpha=0.05$ significance level with $90 \%$ power, 58 subjects were required to complete both treatment periods. The slope coefficient was analysed using analysis of covariance, which included terms for subject, treatment, period and baseline, and was used to estimate the treatment difference and p-value and to calculate the $95 \%$ confidence interval for this difference. The AUC FEV and mean change from pre-dose $\mathrm{FEV}_{1}$ at 12 hours postdose were also analysed using ANCOVA.

Lung function endpoints calculated from the DRC were analysed using analysis of covariance, allowing for effects due to subject, centre, treatment and period.

\section{Results \\ Demography}

A total of 33 subjects were recruited into study A of whom all were randomised and received all three study medications. A total of 206 subjects were recruited into study B of which 75 were randomised, 67 subjects received both SFC and FBC. Of the 131 patients withdrawn prior to randomisation, 118 did not fulfill the entry criteria. There were nine withdrawals post-randomisation in study $\mathrm{B}$, of which seven were due to adverse events. The baseline characteristics of subjects in both studies, including dose of inhaled corticosteroid are shown in Table 1.

\section{Primary endpoints Study A}

Both SFC and FBC increased $\mathrm{FEV}_{1}$ at 16 hours post dose to a similar extent. The improvement from pre-dose baseline was $0.22 \mathrm{~L}$ for SFC and 0.25 L for FBC, which was statistically significant compared with placebo for both treatments $(-0.05 \mathrm{~L} ; \mathrm{p}<0.001)$ (Table 2).

\section{Study B}

For the three primary endpoints of mean change from predose $\mathrm{FEV}_{1}$ at 12 hours, area under the $\mathrm{FEV}_{1}$ curve (weighted mean) over 24 hours, and slope of decline from 2 hours post-dose to 24 hours, both SFC and FBC resulted in a sustained bronchodilation $>12$ hours with no statistical difference between the treatments (Table 3).

\section{Secondary endpoints}

Study A

The mean change in $\mathrm{FEV}_{1}$ from pre-dose baseline was measured for 24 hours following administration of a single inhalation of study medication (Figure 1). At each evaluated time point, the mean change in both the SFC and FBC group was statistically significant compared with placebo and was similar for the two active treatments with no statistical difference between them at any time point (Table 4).

\section{Study B}

Baseline mean $\mathrm{FEV}_{1}$ increased after 4 weeks treatment from $2.75 \mathrm{~L}$ to $2.87 \mathrm{~L}$ for SFC and from $2.78 \mathrm{~L}$ to $2.88 \mathrm{~L}$ for FBC. After 4 weeks regular treatment, the increase in $\mathrm{FEV}_{1}$ from pre-dose over 24 hours was similar to the values measured before 4 weeks treatment with a sustained bronchodilation $>12$ hours and no statistical difference between the treatments (Figures 2 and 3). The adjusted 
Table I: Patient Demography

\begin{tabular}{|c|c|c|}
\hline Characteristic & Study A & Study B \\
\hline Number of subjects screened & 33 & 206 \\
\hline Number of subjects randomised & 33 & $75^{*}$ \\
\hline Mean age (years) (sd) & $40.2(14.3)$ & $36.4(12.5)$ \\
\hline Sex: Males/females \% & $48 / 52$ & $48 / 52$ \\
\hline Mean \% predicted FEV (sd) & $80.5(12.4)$ & $82.8(17.0)$ \\
\hline Mean \% reversibility (sd) & $18.9(6.9)$ & $28.7(17.6)$ \\
\hline \multicolumn{3}{|l|}{ Duration of asthma $(n)$ : } \\
\hline$<5$ years & 2 & 5 \\
\hline $10-20$ years & 9 & 31 \\
\hline$>20$ years & 22 & 39 \\
\hline Current smoker, n (\%) & I (3\%) & $12(16 \%)$ \\
\hline \multicolumn{3}{|l|}{ Dose of ICS at screening for randomised patients (n) } \\
\hline BDP: $200 \mathrm{mcg} b d / 400 \mathrm{mcg}$ bd/500 mcg bd & $2 / 1 / 0$ & $5 / 23 / 15$ \\
\hline Budesonide: $200 \mathrm{mcg} b d / 300 \mathrm{mcg} b d / 400 \mathrm{mcg} b d / 600 \mathrm{mcg}$ bd & $10 / 1 / 13 / 0$ & $0 / 0 / 21 / 1$ \\
\hline FP: $100 \mathrm{mcg} / 250 \mathrm{mcg}$ bd & $2 / 4$ & $2 / 8$ \\
\hline
\end{tabular}

* the majority of screen failures demonstrated insufficient bronchodilator reversibility

mean change from pre-dose baseline in peak $\mathrm{FEV}_{1}$ from 30 minutes to 24 hours post dose was $0.48 \mathrm{~L}$ and $0.53 \mathrm{~L}$ for SFC and FBC prior to 4-weeks treatment (treatment difference SFC-FBC $-0.05 \mathrm{~L} ; 95 \% \mathrm{CI}-0.14,0.04 \mathrm{~L}$ ) and $0.32 \mathrm{~L}$ and $0.37 \mathrm{~L}$ after 4 -weeks treatment (treatment difference SFC-FBC -0.05 L; 95\% CI -0.11, $0.01 \mathrm{~L}$ ).

For diary card parameters, the adjusted mean change from baseline in morning PEF was $25 \mathrm{~L} / \mathrm{min}$ in both the SFC and FBC groups. In addition, the median number of days with no use of relief medication was $63 \%$ in the SFC group and $61 \%$ in the FBC group and the median number of nights with no use of relief medication was also similar with $93 \%$ in the SFC group compared to $89 \%$ in the FBC group. There was no statistical difference between the groups regarding any of these parameters.

\section{Safety}

There were no adverse events reported in study A. In study $B, 32$ subjects in each group experienced an adverse event during treatment of which headache was the most common reported by 9 subjects receiving SFC (12\%) and 13 subjects receiving FBC (19\%). There were no serious adverse events.

\section{Discussion}

A single inhalation of SFC 50/100 mcg or FBC 4.5/160 mcg resulted in a similar, prolonged duration of bronchodilation over 24 hours which was statistically significant when compared with placebo over the whole $24 \mathrm{~h}$ observation period. A comparison of $\mathrm{FEV}_{1}$ before and after four weeks dosing with either SFC 50/100 mcg or FBC 4.5/ $160 \mathrm{mcg}$ twice daily was of a similar duration for each treatment with a small reduction in magnitude, demonstrating a lack of development of clinically important tolerance of the bronchodilating activity with regular administration.

Before starting these studies, we hypothesised that the pharmacological differences of the long-acting $\beta 2$-agonist component of the two combination products could result in a different duration of effect over a 24-hour treatment period $[16,17]$. Thus, in vitro it has been shown that salmeterol has a longer duration of effect than formoterol, but

Table 2: FEV $(\mathrm{L})$ at 16 hours post-dose after a single inhalation of either SFC (50/100 mcg), FBC (4.5//60 mcg) or placebo (Study A).

\begin{tabular}{llll}
\hline & Placebo $(\mathbf{n = 3 3})$ & SFC $(\mathbf{n}=\mathbf{3 3})$ & FBC $(\mathbf{n}=\mathbf{3 3})$ \\
\hline Baseline adjusted mean (se) & $2.74(0.04)$ & $3.01(0.04)$ & $3.03(0.04)$ \\
Adjusted mean change at I6 hours from baseline (se) & $-0.05(0.04)$ & $0.22(0.04)$ & $0.25(0.04)$ \\
& & SFC vs placebo & FBC vs placebo \\
Statistical difference (se) & & $0.27(0.04)$ & $0.29(0.04)$ \\
$95 \% \mathrm{Cl}$ & & $0.19,0.35$ & $0.21,0.37$ \\
$\mathrm{P}$ value & & $<0.001$ & $<0.001$ \\
& & SFC vs FBC & \\
Statistical difference (se) & & $-0.02(0.04)$ & \\
$95 \% \mathrm{Cl}$ & & $-0.10,0.06$ & \\
$\mathrm{P}$ value & & 0.617 & \\
\end{tabular}


Table 3: Analysis of primary endpoints (Study B) prior to 4-weeks regular treatment with SFC (50// 00 mcg) or FBC (4.5//60 mcg)

\begin{tabular}{|c|c|c|c|c|c|}
\hline & \multirow[t]{2}{*}{ SFC $(n=74)$} & \multirow[t]{2}{*}{ FBC $(n=69)$} & \multicolumn{3}{|c|}{ Statistics SFC-FBC } \\
\hline & & & Difference (se) & $95 \% \mathrm{Cl}$ & $P$ value \\
\hline \multicolumn{6}{|c|}{ Slope of decline in FEV $(\mathrm{ml} / \mathrm{hr})$ from 2-24 hours post dose } \\
\hline Adjusted mean (se) & $-15.97(1.91)$ & $-14.15(1.98)$ & $1.82(2.04)$ & $-5.88,2.24$ & 0.375 \\
\hline \multicolumn{6}{|c|}{ Area under FEV, curve (weighted mean, Lxmin) } \\
\hline Adjusted mean (se) & $0.21(0.04)$ & $0.22(0.04)$ & $-0.01(0.04)$ & $-0.09,0.06$ & 0.721 \\
\hline \multicolumn{6}{|c|}{ Mean change from pre-dose $F E V_{1}(L)$ at 12 hours post dose } \\
\hline Adjusted baseline mean (se) & $2.97(0.04)$ & $2.96(0.04)$ & $0.01(0.04)$ & $-0.08,0.09$ & 0.892 \\
\hline Adjusted mean change (se) & $0.21(0.04)$ & $0.20(0.04)$ & & & \\
\hline
\end{tabular}

in clinical studies the duration is the same over 24 hours of monitoring. Therefore, it is important to evaluate the true offset of effect of these drugs beyond the 12 hour time point. A number of studies have shown that both salmeterol and formoterol have a long-lasting clinical efficacy after a single daily dose, which maintains significance above baseline at a 12 hour monitoring time point $[12,13,18-25]$. In the current study (study A), both SFC and FBC produced a similar prolonged bronchodilation beyond 12 hours which was statistically and clinically significant compared with placebo at 16 hours. This is important as subjects may frequently have an interval of up to 16 hours or more between doses which is why 16 hours was chosen as the primary time point for comparison in this study. The peak increase in $\mathrm{FEV}_{1}$ between the two drugs was also similar with the peak effect at 5.6 hours following a single inhalation of both SFC 50/100 mcg and FBC 4.5/160 mcg. Although the difference between both drugs and placebo was statistically significant throughout the 24 hour measurement period, it is unlikely that the difference at the 24 hour point is clinically significant as the lung function values after either treatment approached their respective baseline values.

Formoterol has been shown to have a faster onset of action than salmeterol during the first two hours after inhalation $[12,13,24]$. FBC also has a faster onset of action than SFC with a significant difference in the percentage increase in $\mathrm{FEV}_{1}$ at 3 minutes post $\mathrm{FBC}$ dose compared to a single inhalation of SFC [9]. The difference in early improvement in lung function is however not significant at later time points, which indicates that the difference in bronchodilation between the two combinations diminishes with time. FBC has also been demonstrated to

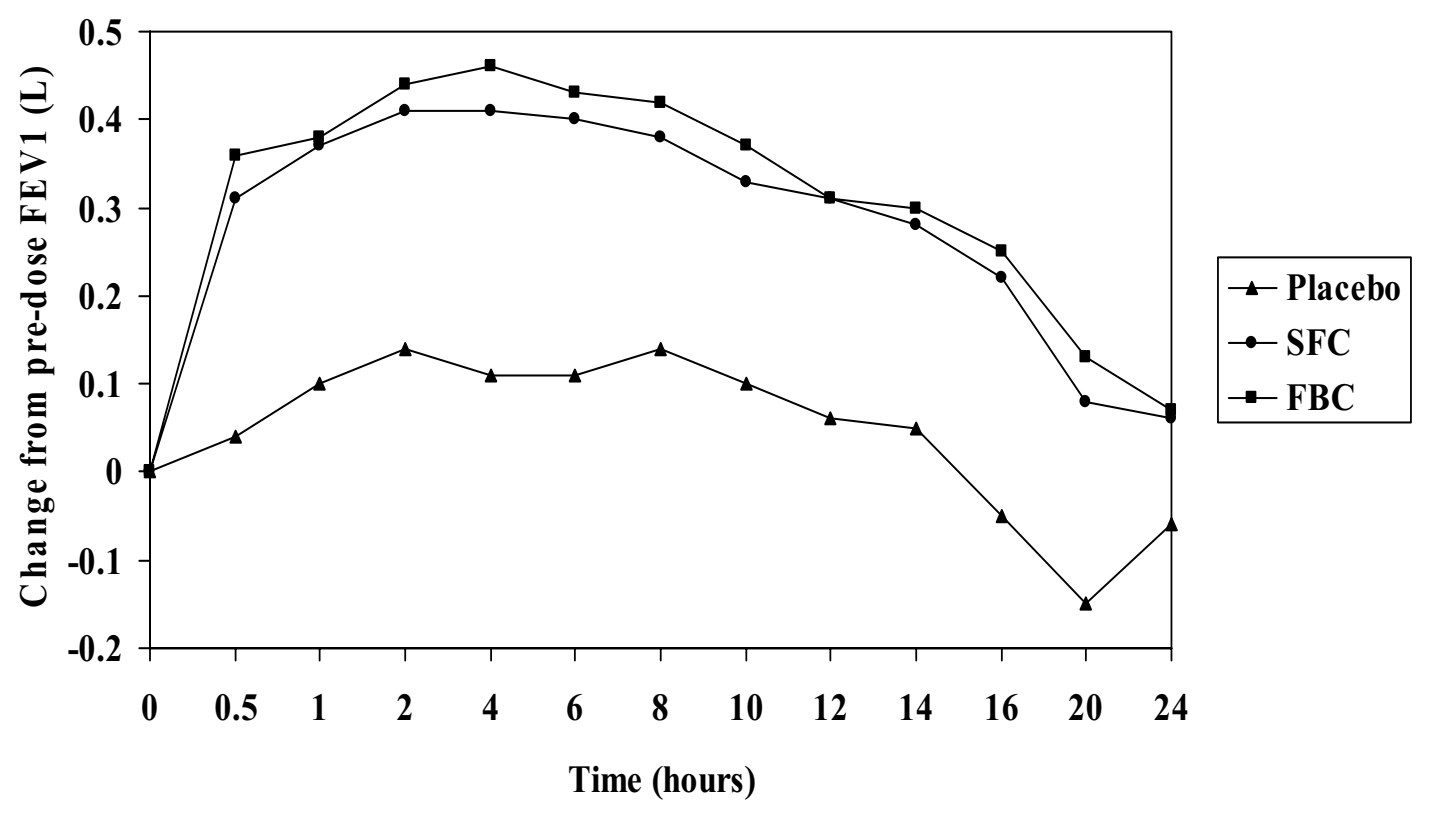

Figure I

Mean FEV, vs time over 24 hours after single inhalation of SFC (50/100 mcg), FBC 4.5/160 mcg or placebo (study A). 
Table 4: Adjusted mean change (se) from pre-dose FEV I (L) over 24 hours after a single inhalation of SFC (50/I 00 mcg), FBC (4.5/I60 mcg) or placebo (Study A).

\begin{tabular}{cccc}
\hline Time post dose $(\mathbf{h r})$ & Placebo & SFC & FBC \\
\hline 0.5 & $0.04(0.02)$ & $0.31(0.02)^{*}$ & $0.36(0.02)^{*}$ \\
1 & $0.10(0.03)$ & $0.37(0.03)^{*}$ & $0.38(0.03)^{*}$ \\
2 & $0.14(0.03)$ & $0.41(0.03)^{*}$ & $0.44(0.03)^{*}$ \\
8 & $0.14(0.04)$ & $0.38(0.04)^{*}$ & $0.42(0.04)^{*}$ \\
12 & $0.06(0.04)$ & $0.31(0.04)^{*}$ & $0.31(0.04)^{*}$ \\
16 & $-0.05(0.04)$ & $0.22(0.04)^{*}$ & $0.25(0.04)^{*}$ \\
20 & $-0.15(0.04)$ & $0.08(0.04)^{*}$ & $0.13(0.04)^{*}$ \\
24 & $-0.06(0.04)$ & $0.06(0.04)^{* *}$ & $0.07(0.04)^{* * *}$ \\
\hline
\end{tabular}

$*_{\mathrm{p}}<0.001$ vs placebo; ${ }^{* *} \mathrm{p}=0.007$ vs placebo; ${ }^{* * *} \mathrm{p}=0.004$ vs placebo.

provide rapid bronchodilation that patients could feel in a situation mimicking an acute state of moderate to severe bronchoconstriction, whereas SFC took longer to produce relief from bronchoconstriction [10]. Although the duration of the study by Palmqvist et al. was sufficient to compare the speed of onset of bronchodilator effect of the combination products, it was insufficient to compare duration of action or to compare time to achieve asthma control, which is more relevant than the onset of bronchodilation for a maintenance therapy.

Present asthma treatment guidelines recommend that the combination of ICS and LABA should be given as maintenance therapy for persistent asthma. In our studies we detected no statistical or clinical difference in $\mathrm{FEV}_{1}$ or other parameters between SFC and FBC at any time point from 30 minutes to 24 hours post dosing. The study was powered to detect a difference in $\mathrm{FEV}_{1}$ between the treatments of $180 \mathrm{ml}$, which was not observed.

The statistically significant difference in $\mathrm{FEV}_{1}$ between placebo and both combinations 24-hours post-dose argues that at least in some patients, once daily administration is possible for maintenance of control. However, the overall evidence of the efficacy of combination treatments in asthma are built on studies with a twice daily regimen and therefore this should remain a general recommendation.

We have also compared the bronchodilator response after four weeks of regular dosing after which any additional

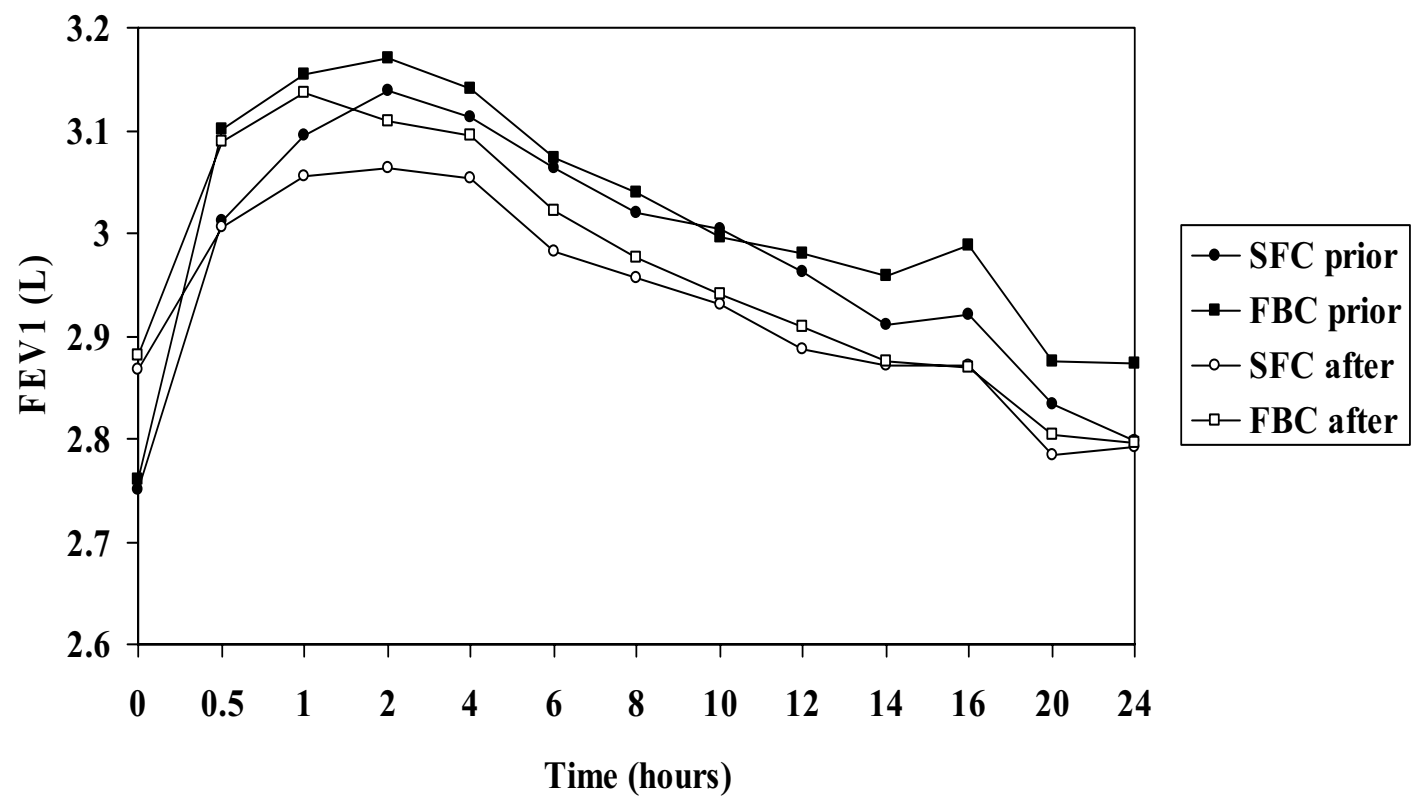

Figure 2

Mean FEV, measurements over 24 hours after the first dose of regular treatment with SFC (50/I00 mcg bd) and FBC (4.5/I60 mcg bd) (study B). 
response attributable to the combination with corticosteroid would be evident (study B). A run-in and wash-out period of four weeks treatment with BDP $800 \mathrm{mcg}$ daily ensured wash-out of any effects of the study drugs. The mean reversibility in $\mathrm{FEV}_{1}$ at inclusion was approximately $19 \%$ showing that subjects had room for improvement. Compared with original baseline treatment, there was an improvement in $\mathrm{FEV}_{1}$ in both groups. After four weeks of regular twice daily dosing, the increase in $\mathrm{FEV}_{1}$ values seen at 12 hours after dosing were less than those obtained prior to 4 weeks treatment. However, because the morning $\mathrm{FEV}_{1}$ prior to dosing of study drugs was higher compared to the first day, which results in less scope for additional bronchodilation. The treatment effect on absolute $\mathrm{FEV}_{1}$ values seen at 12 hours were only slightly lower than those obtained prior to four weeks treatment and the bronchodilation effect was maintained after 8 weeks chronic dosing, which although was reduced, indicated no development of clinical tolerance.

It has been suggested that prolonged administration of long-acting beta-agonists produces tolerance to bronchoprotective stimuli. However, a meta-analysis of nine clinical studies has shown that addition of salmeterol to patients symptomatic on inhaled steroids resulted in protection against bronchoconstrictor stimuli which showed no attenuation after 16 weeks of treatment [26]. Previous data has also shown that chronic dosing with salmeterol does not lead to a reduction in either the peak or the duration of bronchodilator response [27].

An improvement in morning PEF over four weeks regular treatment was also seen in both treatment groups which was of a similar magnitude although this was achieved at half the microgram corticosteroid dose in SFC than FBC. In a direct comparison of both combinations over 12 weeks in symptomatic moderate to severe asthmatics, a similar improvement in lung function was also seen with a dose of SFC which had three times less microgram corticosteroid dose than FBC [28].

In summary, both SFC and FBC resulted in a clinically significant bronchodilation following a single dose. The lung function measured at 16 and 24 hours after dosing was significantly greater than that produced by placebo, with the extent of bronchodilation and the duration of action of SFC and FBC being similar. After four weeks of twice daily treatment there was similar improvement in the baseline lung function with both treatments and the bronchodilator response was not reduced.

\section{Competing interests}

In the last five years, Jan Lötvall has received support for research, and honoraria for lectures and consultations, from AstraZeneca, GlaxoSmithKline, MSD, Schering-
Plough, Novartis and Resistentia Pharmaceuticals. Jan Lötvall's position is financed by the Herman Krefting Foundation against Asthma Allergy.

In the last 5 years, Ashley Woodcock has received support for research, and honoraria for lectures and consultations, from AstraZeneca, Chiesi, GlaxoSmithKline, Novartis, Oriel Therapeutics, Novartis and Schering-Plough.

\section{Acknowledgements}

These studies were sponsored by GlaxoSmithKline Ltd. (protocol numbers: SAM40042/SAM40062)

Seretide $^{\mathrm{TM}}$, Ventolin $^{\mathrm{TM}}$, Diskus ${ }^{\mathrm{TM}}$ and Becotide ${ }^{\mathrm{TM}}$ are registered trademarks of the GlaxoSmithKline group of companies.

Symbicort ${ }^{\mathrm{TM}}$ and Turbuhaler ${ }^{\mathrm{TM}}$ are trademarks of Astra Zeneca.

The authors would like to thank the following investigators who took part in this study; Teet Pullerits, Mona Palmqvist, Birgitta Aronsson, Monica Axelsson, Lotte Edvardsson, Eva Karlgren, Mary-Anne Raneklint, Marianne Robertsson, Helen Törnqvist, David Allen and Sarah Percy.

The authors would also like to thank Dr. Peter Arvidsson for his clinical assistance with the studies.

\section{References}

I. Greening AP, Ind PW, Northfield M, Shaw G: Added salmeterol versus higher-dose corticosteroid in asthma patients with symptoms on existing inhaled corticosteroid. Allen \& Hanburys Limited study group. Lancet I994, 344:2 I 9-24.

2. Condemi JJ, Goldstein S, Kalberg C, Yancey S, Emmett A, Rickard K: The addition of salmeterol to fluticasone propionate versus increasing the dose of fluticasone propionate in patients with persistent asthma. Ann Allergy Asthma Immunol 1999, 82:383-9.

3. Pauwels TA, Lofdahl C-G, Postma DS, Pride NB, Ohlsson SV: Effect of inhaled formoterol and budesonide on exacerbations of asthma. N Engl J Med 1997, 337:|405-II.

4. Aubier M, Pieters W, Schlosser N, Steinmetz KO: Salmeterol/fluticasone propionate $(50 / 500 \mathrm{mcg})$ in combination on a DISKUS inhaler (SERETIDE) is effective and safe in the treatment of steroid dependent asthma. Respir Med 1999, 93:876-84.

5. Kavuru M, Melamed J, Gross G, LaForce C, House K, Prillaman B, Baitinger L, Woodring A, Shah T: Salmeterol and fluticasone propionate combined in a new powder inhalation device for the treatment of asthma: a randomised, double blind placebo controlled trial. J Allergy Clin Immunol 2000, I 05: I I 08- I6.

6. Van den Berg NJ, Ossip M, Hederos CA, Antilla H, Ribeiro BL, Davies $\mathrm{PI}$ : Salmeterol/fluticasone propionate $(50 / 100 \mathrm{mcg})$ in combination in a Diskus inhaler (Seretide) is effective and safe in children with asthma. Paed Pulmonol 2000, 30:97-I05.

7. Zetterström O, Buhl R, Mellem H, Perpina M, Hedman J, O'Neill S, Ekstrom T: Improved asthma control with budesonide/formoterol in a single inhaler, compared with budesonide alone. Eur Respir J 200I, I 8:262-8.

8. Tal A, Simon G, Vermeulen JH, Petru V, Cobos N, Everard ML, De Boeck $\mathrm{K}$ : Budesonide/formoterol in a single inhaler versus inhaled corticosteroids alone in the treatment of asthma. Pediatr Pulmonol 2002, 34:342-50.

9. Palmqvist M, Arvidsson P, Beckman O, Petersen S, Lotvall J: Onset of bronchodilatiation of budesonide/formoterol vs salmeterol/ fluticasone in single inhalers. Pulm Pharmacol The 200I, I 4:29-35.

10. Van der Woude HJ, Boorsma M, Bergqvist PB, Winter TH, Aalbers R: Budesonide/formoterol in a single inhaler rapidly relieves methacholine-induced moderate-to-severe bronchoconstriction. Pulm Pharmacol Ther 2004, I 7:89-95.

II. Van Noord JA, Smeets J], Raaijmakers JAM, Bommer AM, Maesen FP: Salmeterol versus formoterol in patients with moderately 
severe asthma: onset and duration of action. Eur Respir $\int 1996$, 9:1684-8.

12. Ringdal N, Derom E, Wahlin-Boll E, Pauwels R: Onset and duration of action of single doses of formoterol inhaled via BADPI. Respir Med 1998, 92:1017-21.

13. Kemp JP, Bierman CW, Cocchetto DM: Dose-response study of inhaled salmeterol in asthmatic patients with 24-hour spirometry and Holter monitoring. Ann Allergy 1993, 70:316-22.

14. Buhl R, Creemers JP, Vondra V, Martelli NMA, Nava IP, Ekstrom T: Once daily budesonide/formoterol in a single inhaler in adults with moderate persistent asthma. Respir Med 2003, 97:323-30.

15. Goryachkina L, Boonsawat W, Millns H, Balsara S: Seretide/ AdvairTM $50 / 100$ mcg once daily is effective in patients with mild asthma. Am J Respir Crit Care Med 2004, I69(7):A86.

16. Johnson M: Salmeterol. Med Res Rev 1995, 15:225-7.

17. Nials AT, Coleman RA, Johnson M, Magnussen H, Rabe KF, Vardey $C]$ : Effects of $\beta$-adrenoceptor agonists in human bronchial smooth muscle. Br J Pharmacol 1993, I I 0: I I I 2-6.

18. Bootsma GP, Dekhuijen PNR, Fesetn J, Lammers JW, Mulder PG, van Herwaarden CL: Sustained protection against distilled water provocation by a single dose of salmeterol in patients with asthma. Eur Respir J 1997, 10:2230-6.

19. Faurschou P, Engel AM, Haannaes OC: Salmeterol in two different doses in the treatment of nocturnal bronchial asthma poorly controlled by other therapies. Allergy 1994, 49:827-32.

20. Maesen FPV, Smeets JJ, Gubbelmans HLL, Zweers PG: Bronchodilator effect of inhaled formoterol vs salbutamol over 12 hours. Chest 1990, 97:590-4.

21. Arvidsson P, Larsson D, Lofdahl CG: Objective and subjective bronchodilation over 12 hours after inhaled formoterol: individual responses. J Asthma 1993, 30:459-63.

22. Sykes AP, Ayres JG: A study of the duration of the bronchodilator effect of $12 \mathrm{mcg}$ and $\mathbf{2 4} \mathrm{mcg}$ of inhaled formoterol and $200 \mathrm{mcg}$ inhaled salbutamol in asthma. Respir Med 1990, 84: $135-8$.

23. Pohunek P, Matulka M, Rybnicek O, Kopriva F, Honomichlova H, Svobodova T: Dose-related efficacy and safety of formoterol (Oxis) Turbuhaler compared with salmeterol Diskhaler in children with asthma. Pediatr Allergy Immunol 2004, I 5:32-9.

24. Palmqvist M, Persson L, Lazer J, Rosenborg J, Larsson P, Lotvall : Inhaled dry-powder formoterol and salmeterol in asthmatic patients: onset of action, duration of effect and potency. Eur Respir J 1997, 10:2484-9.

25. Rabe KF, Jorres R, Nowak D, Behr N, Magnussen $H$ : Comparison of the effects of salmeterol and formoterol on airway tone and responsiveness over $\mathbf{2 4}$ hours in bronchial asthma. Am Rev Respir Dis 1993, 147: 1436-41.

26. Verberne AA, Fuller R: An overview of nine clinical trials of salmeterol in an asthmatic population. Respir Med 1998, 92:777-82.

27. Pearlman D, Chervinsky P, LaForce C, Seltzer JM, Southern DL, Kemp JP, Dockhorn RJ, Grossman J, Liddle RF, Yancey SW: A comparison of salmeterol with albuterol in the treatment of mild to moderate asthma. N EnglJ Med 1992, 327:1402-5.

28. Ringdal N, Chuchalin A, Chovan L, Tudoric N, Maggi E, Whitehead P: Evaluation of different inhaled combination therapies (EDICT): a randomised, double blind comparison of Seretide (50-250 mcg bd Diskus vs. formoterol ( 12 mcg bd) and budesonide ( $800 \mathrm{mcg}$ bd) given concurrently (both via Turbuhaler) in patients with moderate-to-severe asthma. Respir Med 2002, 96:85I-6I.
Publish with Biomed Central and every scientist can read your work free of charge

"BioMed Central will be the most significant development for disseminating the results of biomedical research in our lifetime. "

Sir Paul Nurse, Cancer Research UK

Your research papers will be:

- available free of charge to the entire biomedical community

- peer reviewed and published immediately upon acceptance

- cited in PubMed and archived on PubMed Central

- yours - you keep the copyright

Submit your manuscript here:

http://www.biomedcentral.com/info/publishing_adv.asp
BioMedcentral 